\title{
Climate change governance
}

\section{Working Paper}

\section{Author(s):}

Bernauer, Thomas; Schaffer, Lena Maria

\section{Publication date:}

2010

Permanent link:

https://doi.org/10.3929/ethz-a-006309785

Rights / license:

In Copyright - Non-Commercial Use Permitted

Originally published in:

IED working paper 12 


\section{Climate Change Governance}

Thomas Bernauer

Lena Maria Schaffer 


\section{About the authors:}
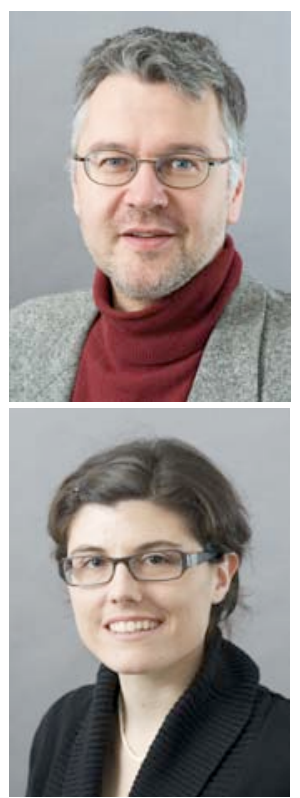

Thomas Bernauer is a professor of political science at ETH Zurich. In his research and teaching he focuses on international environmental and economic issues. That is, he analyzes political and other conditions under which environmental and economic problems that extend beyond national borders can be solved. He is the author or co-author of ten books, more than 60 journal articles or book chapters, and many other types of publications. His publications have appeared with publishers such as Princeton University Press as well as in political science, economics, and natural sciences journals, for example International Organization, British Journal of Political Science, European Journal of Political Research, Ecological Economics, World Development, and Water Resources Research.

Lena Maria Schaffer is a Ph.D. student in Thomas Bernauer's group at ETH Zürich. In her dissertation, Lena investigates the interdependencies in decision-making between local governments within the United States with a special focus on voluntary climate change policy. 


\section{Climate Change Governance}

\section{Thomas Bernauer and Lena Maria Schaffer}

\section{ETHZürich}

Center for Comparative and International Studies (CIS) and

Institute for Environmental Decisions (IED)

WEC C.2O; Weinbergstrasse 11

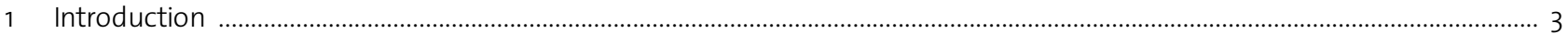

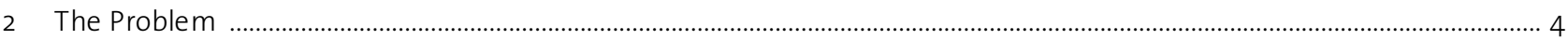

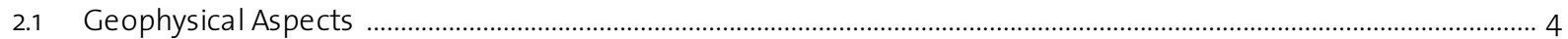

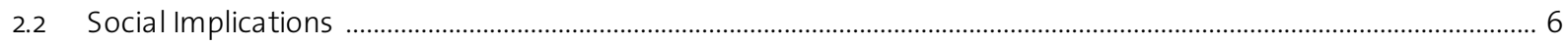

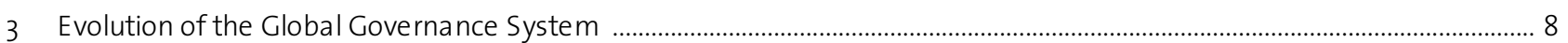

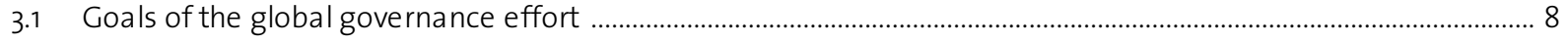

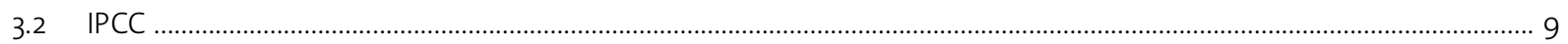

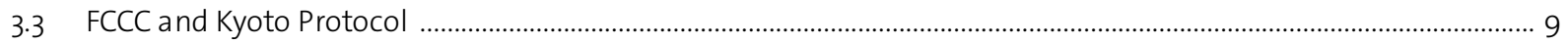

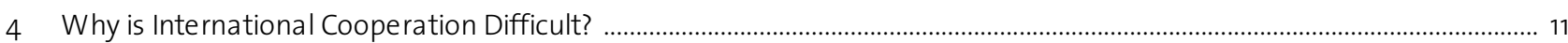

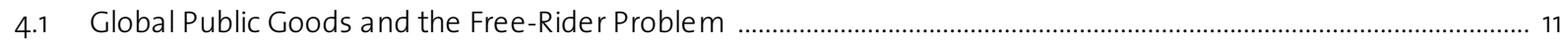

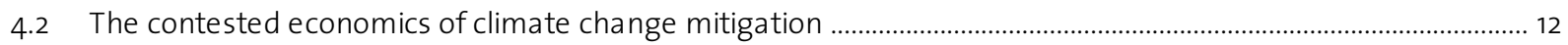

5 Measuring and Explaining Variation in National Contributions to the Global Public Good ................................................... 13

5.1 Measuring Variation in Contributions to the Public Good ...................................................................................... 13

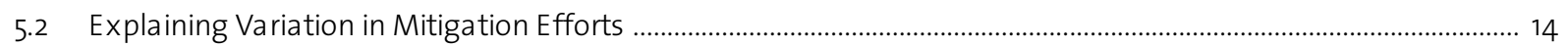

6 Alternative Forms of Climate Change Governance: Local Dynamics in Federal Systems ...................................................... 17

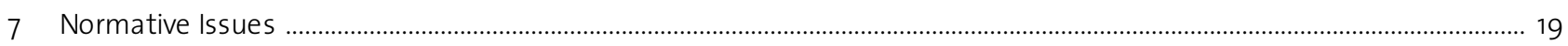

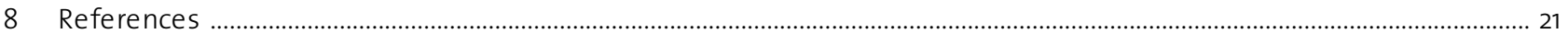




\section{Introduction}

Within less than three decades, climate change has developed from a rather obscure scientific topic into a key item on the global political agenda. It has also attracted strong attention in many areas of scientific research, including the social sciences. Social scientists, and notably governance specialists focusing on climate change have addressed a wide range of important questions, including the following:

- What are the key political challenges in establishing and implementing governance systems to cope with climatic changes?

- Why are some countries in the international system more cooperative than others in this respect?

- To what extent can local efforts in climate policy support national and global efforts?

- What are the main normative issues associated with climate change policy, notably, how should the costs and benefits associated with solving the problem be distributed across countries and time?

- Which policy instruments are likely to be more effective and/or efficient in dealing with climate change?

In this contribution we focus mainly on the first four of these questions. The existing literature on particular climate policy instruments (e.g. carbon taxes, tradable permits, joint implementation) is very large and has been summarized elsewhere (e.g. Stavins 2003).

1 These include regulations and standards, taxes and charges, tradable emissions permits, subsidies and tax credits, voluntary agreements between industry and government, awareness campaigns, government sponsored and/or subsidized R\&D, and integration of climate policy objectives in development, trade, and investment policies.

We start with an overview of the climate change problem (section 2), followed by a discussion of international institutions that have thus far been established to cope with the challenge (section 3). We then look at the reasons why global cooperation for climate change mitigation is difficult to achieve (section 4). Section 5 shows that, even though cooperation at the global level is difficult, there is strong variation in countries' level of effort in this respect. We examine how levels of effort can be measured and how variation in effort can be explained. After having moved from the global (systemic) to the national level of analysis, we also explore climate policy-making at the sub national level (section 6). Local policy-making is, from an analytical viewpoint, particularly interesting in the case of federal political systems. The chapter ends in section 7 with a brief discussion of normative issues. 


\section{The Problem}

\subsection{Geophysical Aspects}

In contrast to the weather, which is highly variable both spatially and temporally, the global climate is much more stable. It can be regarded as the Earth's average weather and/or its variability over longer periods of time (typically at least decades). Whereas the weather can be experienced directly by humans, the climate is a scientific (essentially statistical) construct. For instance, while temperatures can easily vary by $20^{\circ} \mathrm{C}$ in a particular location within a single day, the average global temperature does not vary by more than $1-5^{\circ} \mathrm{C}$ within time-spans of thousands of years.

Changes in the Earth's climate took place also in premodern times (before the industrial revolution). Such changes occurred due to non-human factors, e.g. changes in heat output of the sun and volcanic activity. However, starting in 1896 with the Swedish chemist Svante Arrhenius, scientists have produced a mounting stream of evidence demonstrating that so called greenhouse gases (GHG) emitted by human activities are influencing the Earth's climate as well.

Several gases in the atmosphere, most notably water vapor and carbon dioxide $\left(\mathrm{CO}_{2}\right)$, are instrumental in trapping some of the sun's energy to which the Earth is exposed. This greenhouse effect is essential for life on Earth. Without this heat trapping the Earth would be more than $30{ }^{\circ} \mathrm{C}$ colder. Yet, human activity, in particular the combustion of fossil fuels (coal, oil, gas) and land-use changes, have led to a large increase in concentrations of GHGs in the atmosphere. Atmospheric concentrations of the two most important GHGs emitted by human activity, $\mathrm{CO}_{2}$ (carbon dioxide) and $\mathrm{CH}_{4}$ (methane) ${ }^{2}$, were far higher in the

\footnotetext{
2 Other important GHGs include nitrous oxide $\left(\mathrm{N}_{2} \mathrm{O}\right)$ and halocarbons.
}

year 2005 than the natural range of these gases in the past 650.000 years. $\mathrm{CO}_{2}$ has increased from a preindustrial (i.e. prior to about 1750) level of $280 \mathrm{ppm}$ to $379 p p m$ in 2005, and $\mathrm{CH}_{4}$ from 715 to 1774 ppm (IPCC 2007).

Climate scientists have over the past several decades invested an enormous amount of effort in trying to understand the causal pathways leading from

1. vastly increased anthropogenic GHG emissions since the industrial revolution (with a $70 \%$ growth in 1970 2004 alone) to

2. growing atmospheric concentrations of GHGs to

3. changes in radiative forcing to

4. changes in temperature (about $0.75^{\circ} \mathrm{C}$ over the past 100 years, with more warming in northern latitudes, and greater warming over land than over the oceans) and precipitation to

5. various effects of changes in temperature and precipitation on plants, animals, and humans.

The Intergovernmental Panel on Climate Change (IPCC, c.f. section 3.2), a large global network including thousands of scientists and also policy-makers, has so far issued four comprehensive reports. These reports summarize and assess the available scientific evidence on the causes and implications of climate change, as well as policy options for coping with the problem. The IPCC stands out, by orders of magnitude, as the largest and most tightly organized science-policy nexus in the history of governance efforts in any policy-area we can think of.

This unprecedented scientific effort has over the past two decades resulted in increasingly firm international agreement that anthropogenic GHG emissions are responsible for a large part of the observed global warming trend. Interestingly, the main conclusion from this scientific effort is rather close to what Arrhenius argued more than 100 years ago; that a doubling of $\mathrm{CO}_{2}$ concentrations in the 
atmosphere would increase global average temperature by around $5^{\circ} \mathrm{C}$ (current estimates are around 1.5 to 4.5 degrees). More generally, the IPCC (2007: 10) notes that: "Most of the observed increase in globally averaged temperatures since the mid-2oth century is very likely due to the observed increase in anthropogenic (human) greenhouse gas concentrations."

Figure 1 illustrates that computer models trying to reconstruct the empirical climate record tend to perform better once anthropogenic emissions are included alongside nonhuman drivers of climatic changes.
While ex post explanation of climatic changes in terms of anthropogenic GHG emissions is very complex, prediction of future temperature and precipitation is even more challenging. The main reason is that, besides incomplete understanding of geophysical mechanisms, there is great uncertainty concerning future GHG emissions. For instance, depending on assumptions about technological innovations, economic growth (which in itself is hard to predict over several decades) may be associated with very different levels of emissions.

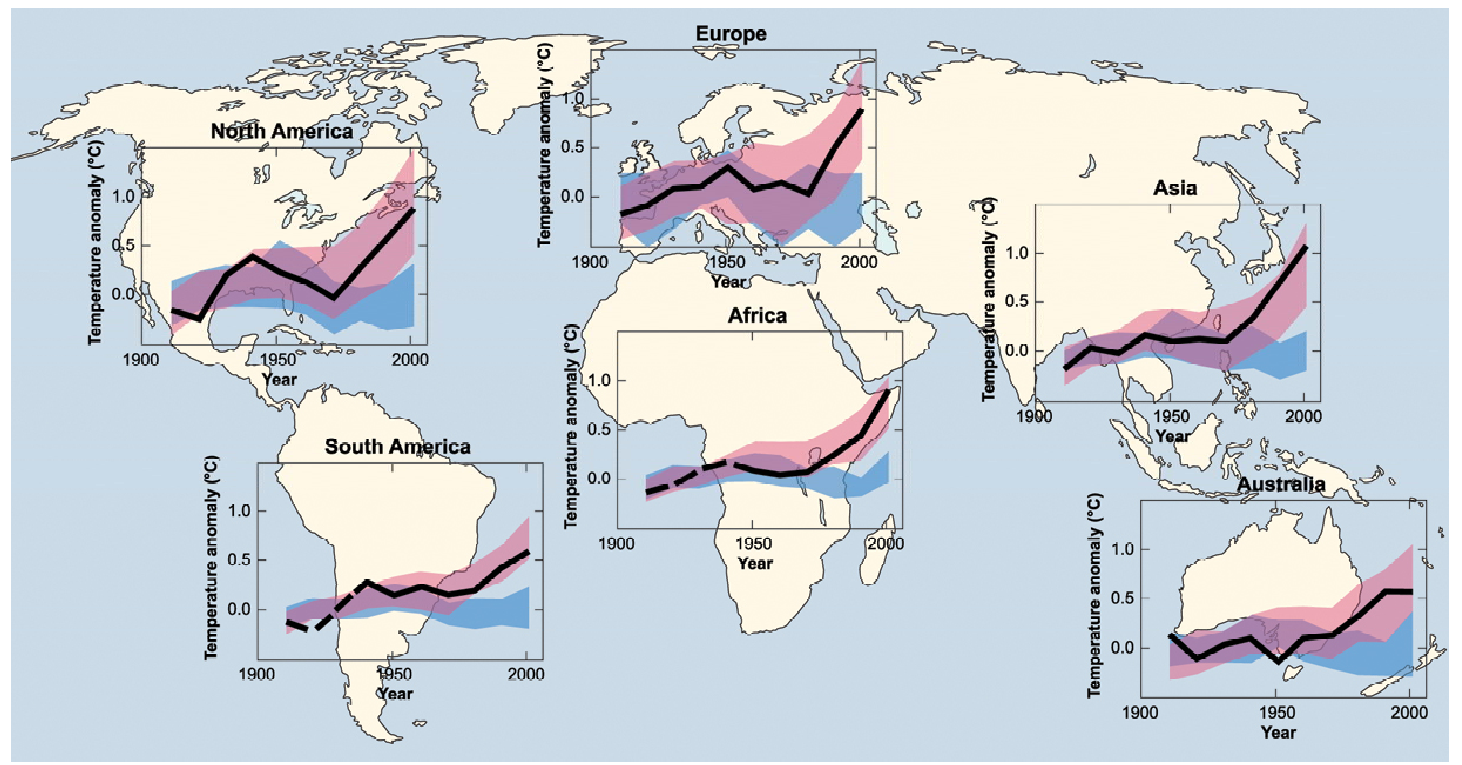

Figure 1: Comparison of climate model predictions with empirical climate records. Blue = models including only natural causes. Red = models including natural and a nthropogenic causes. Black line $=$ decadal averages of observations 1906-2005 plotted against the centre of the decade and relative to the corresponding average for 1901-1950. Dashed line = spatial coverage less than $50 \%$. Blue shaded bands $=5$ to $95 \%$ range for 19 simulations from five climate models using only the natural forcings (solar activity, volcanoes). Red shaded Bands: 5 to $95 \%$ range for 58 simulations from 14 climate models using both natural and a nthropogenic forcings (Source: IPCC 2007).

As illustrated by Figure 2 , one IPCC scenario (A1FI) assumes rapid economic growth, rapid introduction of new and more efficient but fossil fuel intensive technologies, a mid century peak of global population, and a substantial reduction in regional differences in per capita income. In this scenario, global GHG emissions are predicted to increase

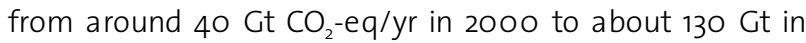
2100. Another IPCC scenario (B1) assumes a convergent world with the same population, but rapid changes in economic structures toward a service and information economy, the introduction of clean and resource efficient technologies, and an emphasis on global solutions to problems of environmental sustainability. In this scenario,

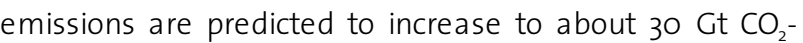
eq/yr by 2100 (IPCC 2007, Special Report on Emissions scenarios). 


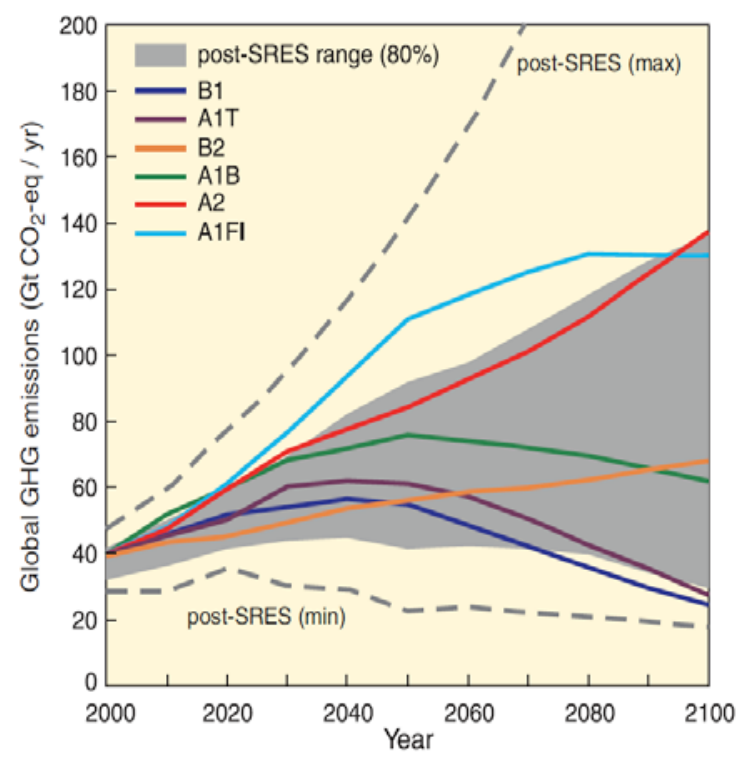

Figure 2: GHG emissions scenarios: global GHG emissions (in $\mathrm{GtCO}_{2}$-eq per year) in the absence of additional climate policies: six illustrative SRES marker scenarios (coloured lines) and 8oth percentile range of scenarios published since SRES (post-SRES) (gray shaded area). Dashed lines show the full range of post- SRES scenarios. The emissions include $\mathrm{CO}_{2}, \mathrm{CH}_{4}, \mathrm{~N}_{2} \mathrm{O}$ and F-gases (Source: IPCC 2007).

Because GHGs are quite long-lived, even very optimistic emissions scenarios are likely to result in considerable global warming. The IPCC (2007: 46ff.) notes that:

„Anthropogenic warming and sea level rise would continue for centuries due to the timescales associated with climate processes and feedbacks, even if greenhouse gas concentrations were to be stabilized, although the likely a mount of temperature and sea level rise varies greatly depending on the fossil intensity of human activity during the next century [...]. The probability that this is caused by natural climatic processes alone is less than $5 \%$...World temperatures could rise by between 1.1 and $6.4{ }^{\circ} \mathrm{C}$ during the 21st century. Sea levels will probably rise by 18 to $59 \mathrm{~cm}[. .$.$] .$ There is a confidence level $>90 \%$ that there will be more frequent warm spells, heat waves and heavy rainfall [...]. There is a confidence level $>66 \%$ that there will be an increase in droughts, tropical cyclones and extreme high tides [...]. Both past and future anthropogenic carbon dioxide emissions will continue to contribute to warming and sea level rise for more than a millennium."

\subsection{Social Implications}

The projected social implications of climatic changes depend very much on projected emissions and their radiative forcing. The IPCC's (2007) best estimates range from $+0.6^{\circ} \mathrm{C}$ by 2090-2099, compared to 1980-1999, in the case of continuing year 2000 concentrations (which is next to impossible in view of still growing global emissions), to $+2.8^{\circ} \mathrm{C}$ in a moderately optimistic scenario $(\mathrm{A} 1 \mathrm{~B})$, to $4.0^{\circ} \mathrm{C}$ and more in pessimistic scenarios. Projected sea level rise by the end of the 21st century is up to 0.59 meters in the standard scenarios. In extreme scenarios, such as those involving a complete loss of the Greenland and West Antarctica ice sheets, sea levels could rise by 7 meters or more.

Besides the large natural sciences literature on the implications of climate change for weather patterns, water availability, natural disasters, plants, animals, and ecosystems, a considerable social sciences literature on climate change implications has developed as well. This literature seeks to clarify the social, economic, political and security implications of climate change.

The largest part of existing social sciences research examines climate change implications in terms of economic losses and other forms of social damage (e.g. changing livelihoods, public health problems, migration), as well as adaptive capacity (e.g. Adger 2010, Füssel 2010). By and large, this research arrives at the conclusion that poorer countries are at greatest risk, both in terms of exposure to climatic changes and sensitivity to such changes, and in terms of their capacity to adapt. Exposure, sensitivity, and capacity to adapt determine how vulnerable particular countries or social groups are to climatic changes (Füssel 2010).

Social scientists have also sought to quantify overall effects of climatic changes on economic growth in the past and project economic losses under different emissions and mitigation scenarios into the future (e.g. Stern et al. 2006, Stern 2008). Ex post statistical analysis has thus far produced some evidence that higher temperature and lower precipitation are associated with lower economic growth, particularly in Africa, though these findings are not very robust (e.g. Miguel et al. 2004, Dell et al. 2008, Bernauer et al. 2010). 
Estimates of future effects on economic growth under different climate scenarios are based on so called integrated assessment models that explore national, regional, and global cost implications. The findings from these models vary enormously. Having reviewed many such studies, the IPCC (2007) for instance concludes: „Global mean losses could be $1-5 \%$ of GDP for 4 degrees of warming, but regional losses could be substantially higher." Yet, as illustrated by Figure 3, cost implications reported by the influential Stern Review (Stern et al. 2006) are substantially larger than estimates provided by other scientific reports.

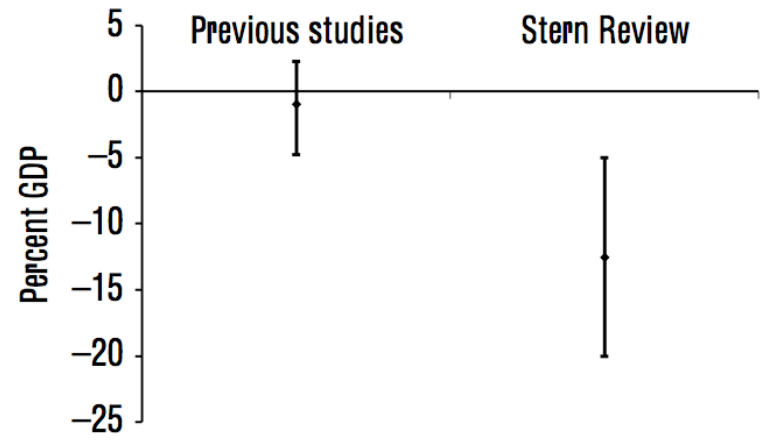

Figure 3: Estimates of damage resulting from unmitigated climate change. Source: Tol and Yohe 2006.

One of the principal sources of vast differences in estimated costs of unmitigated climate change (i.e. costs in the absence of international cooperation and GHG emissions cuts) is the discount rate. The discount rate captures the extent to which future losses are less important economically than present losses. The reasons for discounting future losses are that people generally prefer the present to the future, that consumption will be higher in the future due to increased wealth (with decreasing marginal utility), that future consumption levels are uncertain, and that future technology may make it cheaper to cut emissions then. The higher the discount rate used to deflate the stream of future losses to a present value, the lower is the presently valued damage from future climate change. For instance, if we assume an annual discount rate of $3 \%, a$ climate damage of $\$ 100$ occurring in 25 years is worth only $\$ 50$ today. While some economists (e.g. Nordhaus 2010) use standard discount rates from the investment world (around 2-3\%), others (e.g. Stern 2008, Cline 1999) argue that such discount rates are too high. They use discount rates in the order of $1-2 \%$, which are close to real interest rates for government bonds. The choice of discount rate has important implications for the assessment of governance options and involves strong normative components, to which we return in the final section of the chapter (see final section of the chapter).

Repeated statements by high-ranking politicians about climate change-related wars have triggered yet another intense research effort in which social scientists are examining the validity of this claim. US President Obama, for instance, claimed in $2009^{3}$ that

"The threat of climate change is serious, it is urgent and it is growing [...] The security and stability of each nation and all peoples - our prosperity, our health, our safety - are in jeopardy. And the time we have to reverse this tide is running out."

The most likely scenario for an interstate war involves competition over scarce international water resources, food and energy, or mass migration (for extreme scenarios, see Schwartz and Randall 2003). Interestingly, existing research offers virtually no historical evidence for climate related international wars. Whether climate change could increase the probability of intrastate (i.e. civil) war is more strongly debated. A few studies (e.g. Burke et al. 2009) identify such an effect for Africa in the 1980s and 1990 s and make rather worrying projections for the future. Yet, these findings remain very much contested and other authors, using similar data, do not find a significant effect of climatic changes on the probability of intrastate war (e.g. Buhaug et al. 2008; Theisen et al. 2010; Bernauer et al. 2010)

\footnotetext{
3 Delivering a speech at the climate change summit of the United Nations on 22nd of September 2009
} 


\section{Evolution of the Global Governance System}

As noted above, science plays a major role in climate policy. Hence we start by discussing what are, from the viewpoint of many scientists and policy-makers, the basic goals of the global governance effort. We then describe the IPCC, the principal global institution for knowledgegeneration in this policy area. Finally we discuss the UN Framework Convention on Climate Change (FCCC) and the Kyoto Protocol (KP). The latter two are, from a legal viewpoint, the backbone of the existing global governance system.

\subsection{Goals of the global governance effort}

A strong global consensus has emerged over the past few years that climatic changes must be addressed through mitigation of GHG emissions and, because some major climatic changes are unavoidable even with extremely ambitious mitigation efforts, adaptation. The key questions in this respect are:

1. by how much should GHG emissions be reduced, and in what time frame?

2. how much would this cost, and how should the burden be distributed among countries and over time?

3. how much should be invested in adaptation and who should pay for it?

(1) The policy positions of many countries have, over the past few years, converged on the goal of limiting the global average temperature increase to $2^{\circ} \mathrm{C}$, relative to the mid-18th century level. From the perspective of most scientists, a temperature target makes more sense than an emissions or concentrations target because it is ultimately temperature that affects ecosystems and humanity. The $2^{\circ} \mathrm{C}$ target emerged from discussions among scientists and policy-makers in Germany in the mid-1990s. The $2^{\circ} \mathrm{C}$ temperature increase was initially used as a rather arbitrarily chosen parameter to examine climate change impacts, e.g. impacts on the Earth's major ice sheets. When many models indicated major damages or uncertainties beyond that level (e.g. with respect to the long-term stability of the Greenland ice sheet), the two degrees developed into a political target, even though there is no clear-cut scientific reason for this particular choice.

Recent calculations by Allen et al. (2009) show that it would be necessary to limit total $\mathrm{CO}_{2}$ emissions in the $2000-2050$ period to 1000 billion tons in order to meet the $2^{\circ} \mathrm{C}$ target. One third of this $\mathrm{CO}_{2}$ budget has already been used in 2000-2009. Consequently, emissions would have to be cut by $50 \%$ by 2050 , which would implicate reductions of $25-40 \%$ by industrialized countries until 2020 , and $80-95 \%$ until 2050 . These targets are, by and large, in line with IPCC 2007 statements and the Stern Review.

(2) Various studies have tried to estimate by how much global carbon prices (the total cost an emitter of a unit of GHG would have to pay for) would have to increase in order to reach specific reduction targets. The IPCC (2007) for instance notes a figure of $\$ 20-80$ per ton of $\mathrm{CO}_{2}$ equivalent by 2030 to stabilize $\mathrm{GHG}$ concentrations at 550 ppm (roughly a doubling of pre-industrial concentrations, which were 280 ppm then and 379ppm in 2005) by 2100. Optimistic studies indicate \$5-\$65 (IPCC 2007).

The IPCC's best estimates of the costs of stabilizing GHG concentrations at 535-590ppm, which would probably meet the $2^{\circ} \mathrm{C}$ target, are in the order of a $0.1 \%$ reduction of average annual GDP growth rates. The Stern Report arrives at a similar estimate.

On the more pessimistic side, Nordhaus (2010) estimates that reaching the $2^{\circ} \mathrm{C}$ target would require a carbon price of $\$ 64$ in 2010 (at 2005 prices), whereas the global average price today is around $\$ 5$, and rapid growth of this price over the next few years. 
How to share the burden of GHG reductions remains disputed. At the most general level, there is agreement that industrialized countries must shoulder most of the mitigation costs over the coming decades. The Kyoto Protocol (see below) in fact assigns that responsibility to this group of countries in the 2008-2012 period. But there is no consensus on how to deal with very large, and rapidly growing developing countries, notably Brazil, China, and India. We return to this point in the final section of the chapter.

(3) As noted by the IPCC (2007): „Much less information is available about the costs and effectiveness of adaptation measures than about mitigation measures." In any event, the costs are likely to be high and can most probably not be met by poor countries, which tend to be most vulnerable to climatic changes. Estimates of adaptation costs range from lower two digit billion figures to $\$ 200$ billion and more per year. At the Copenhagen conference in late 2009, industrialized countries promised adaptation support in the order of $\$ 100$ billion per year in the future. But it remains unclear how firm the se promises really are, how much each industrialized country would contribute, and how the funding mechanism should be designed.

\subsection{IPCC}

The IPCC is an intergovernmental institution. Its task is to summarize and assess existing scientific knowledge on human-induced climate change and its impacts, as well as options for mitigation and adaptation. It was set up in 1988 by the UN World Meteorological Organization (WMO) and the UN Environment Programme (UNEP). Its secretariat is located in Geneva, Switzerland. Its activities are funded by WMO, UNEP, and by direct contributions from governments.

The IPCC does not carry out „in-house“ research, nor does it act as a monitoring agency in implementing global climate agreements (see below). It acts primarily as manager of a large network of scientists worldwide. Its activity centers around so called Assessment Reports. Such reports have thus far been published in 1990/92, 1995, 2001 and 2007. The next report is scheduled for 2014. The scientists involved, usually several thousand from more than one hundred countries, review the relevant scientific literature and, with the help of lead editors, summarize and assess the existing knowledge. This process is organized in three working groups: Working Group I examines geophysical aspects of the climate system and climate change; Working Group II examines vulnerability of socio-economic and natural systems to climate change, consequences, and adaptation options; and Working Group III examines options for limiting greenhouse gas emissions and mitigating climate change in other ways.

The IPCC also includes a „Task Force on National Greenhouse Gas Inventories". In the judgment of most observers, the work on the Assessment Reports proceeds largely according to scientific criteria of due diligence. However, the synthesis work and summaries for policy-makers are also exposed to political influence because the Panel, which is composed of government delegates from all member countries, ultimately decides on their adoption. Hence the wording in the summary for policy-makers (but not the content of the detailed reports by the working groups) is subject to some political negotiation. However, governments have thus far hesitated to modify, for political purposes, the main conclusions drawn from scientific assessments.

\subsection{FCCC and Kyoto Protocol}

The United Nations Framework Convention on Climate Change (FCCC) was formally adopted at the Rio, or Earth Summit in 1992 (UN Conference on Environment and Development, UNCED). Its aim is the

„stabilization of greenhouse gas concentrations in the atmosphere at a level that would prevent dangerous anthropogenic interference with the climate system. Such a level should be achieved within a time-frame sufficient to allow ecosystems to adapt naturally to climate change, to ensure that food production is not threatened and to enable economic development to proceed in a sustainable manner." (Art. 2, FCCC)

This global treaty does not set forth mandatory emission constraints, overall or for specific countries. Yet it has established the basic legal structure for future agreements and has defined, at a very general level, the goals to be achieved in climate policy. The FCCC entered into force in March 1994 and, as of late 2009, has attracted 192 member countries. Supported by the IPCC Task Force on National Greenhouse Gas Inventories and the FCCC secre- 
tariat in Bonn, Germany, the FCCC members have established national inventories of greenhouse gas (GHG) emissions and removals. These inventories served to identify the 1990 emission levels that are the benchmarks for emission reduction obligations under the Kyoto Protocol. The so-called Annex I countries (OECD countries and transition economies) are committed to periodically update these inventories.

Since 1995 the member countries of the FCCC have met each year in Conferences of the Parties (COP). These meetings serve to review the implementation of the agreement and negotiate follow-up agreements. The most important outcome thus far is the Kyoto Protocol (KP). This Protocol was adopted in December 1997 and entered into force in February 2005 (after 55 countries representing $55 \%$ of global $\mathrm{CO}_{2}$ emissions in 1990 had ratified). The Protocol has (as of late 2009) 187 countries that have ratified it. The most important holdouts are the United States, Afghanistan, Somalia, and Taiwan.

Under the KP, industrialized countries (Annex I countries) have undertaken to reduce six GHGs (carbon dioxide, methane, nitrous oxide, sulphur hexafluoride, hydrofluorocarbons, and perfluorocarbons ${ }^{4}$ ), of which carbon dioxide and methane are the most important in terms of the size of their greenhouse effect. 39 of 40 potential Annex I countries (except the USA) have ratified, and 34 countries have committed to emission reductions - 5 of the KP Annex I members are allowed to maintain or increase their 1990 emission levels (e.g. Russia, Australia, Iceland). The European Union is treated as a "bubble": it received a single target and then allocated emission rights to its member countries. Total reductions are supposed to be in the order of $5.2 \%$ by 2012, from the 1990 level (each GHG is weighed by its global warming potential). The KP also provides for "flexible mechanisms", such as emissions trading, the clean development mechanism, and joint implementation. The purpose of these economic instruments is to make GHG emissions cuts more cost-efficient, with the assumption that countries are willing to curb the ir emissions more if doing so is cheaper. Monitoring of compliance relies primarily on annual reports of GHG emissions by Annex I countries and (on a voluntary basis) by other countries.

Most observers of the KP agree that many Annex I countries a re currently experiencing difficulties in meeting their emissions targets domestically and are likely to make use of flexible mechanisms in order to be able to meet their legal obligations. Also, the USA, which has not ratified the $\mathrm{KP}$ but could still implement its Kyoto targets voluntarily, has increased its emissions quite dramatically (its Kyoto target was $-7 \%$ relative to the 1990 level). Moreover, negotiations on a follow-up agreement to the KP, which ends in 2012, have thus far failed, most recently in Copenhagen. A recent study (Rogelj et al. 2010) suggest that, even if all unilateral reduction pledges made at Copenhagen were implemented, the probability of limiting global warming to $3^{\circ} \mathrm{C}$ by 2100 would only be $50 \%$, while global emissions would increase by $20 \%$ over 2010 levels. If emissions were cut by $50 \%$ by 2050 the probability of exceeding $2^{\circ} \mathrm{C}$ would still be $50 \%$.

\footnotetext{
${ }_{4} \mathrm{CO}_{2}, \mathrm{CH}_{4}, \mathrm{~N}_{2} \mathrm{O}, \mathrm{HFC}, \mathrm{PFC}, \mathrm{SF}_{6}$.
} 


\section{Why is International Cooperation Difficult?}

GHG reduction targets set forth in existing governance arrangements are still far from what would be required to limit temperature increases to $2^{\circ} \mathrm{C}$. It remains unclear whether those rather non-ambitious targets will be reached by 2012, and even greater uncertainty exists with respect to unilateral pledges for the post-2012 period and the prospects for formal, follow-up international agreements.

At the most general level, namely the global political and economic system, climate change mitigation is difficult because it has the character of a global public good. Moreover, there is considerable disagreement over the costs and benefits of GHG mitigation. We discuss these two problems in this section. The following section (section 5) sheds light on additional challenges to effective governance that emanate from country characteristics, such as differences in economic conditions and political institutions, which make some countries more reluctant to cooperate than others.

\subsection{Global Public Goods and the Free-Rider Problem}

Climate change mitigation is one of the most typical public goods problems imaginable. Efforts to reduce GHGs correspond by and large to an $\mathrm{N}$-actor prisoner's dilemma, which is similar to the tragedy of the commons (Hardin 1968). The Earth has one indivisible atmosphere that can be used as a sink for GHG emissions worldwide; i.e. it is a common pool resource characterized by open access and rivalry in consumption (Ostrom et al. 1994). By implication, GHG reductions by any country generate costs and benefits (in terms of avoided damages) for that country, but also benefits for other countries (positive externalities). Because in the climate case positive externalities from emission cuts are quite large in relation to national benefits, international cooperation is necessary, but countries are reluctant to do so.
For example, if Italy or Ireland were to cut its GHG emissions by $20 \%$, but no other country did the same, this reduction would probably create some local benefits of a non-climatic nature (e.g. less local air pollution, more technological innovation) and some, albeit minuscule climatic benefits. But the overall net benefit for the respective country would probably be very small and could even be negative. Assuming that countries follow a rationalist, interest-based logic when deciding on their climate policy, they will not implement any major unilateral GHG emission cuts unless other countries credibly commit to a similar policy (e.g. Sandler 1997; Barrett 2003; Mitchell 2006). The Kyoto Protocol reflects this problem very clearly: it requires ratification by 55 countries representing $55 \%$ of global emissions before entry into force. This clause protects countries from getting "caught up" in legal obligations to reduce emissions if they ratify early but other countries (and major emitters in particular) end up not joining.

In essence, global governance in climate change policy uses mechanisms of reciprocity to prevent free riding on positive externalities. Reciprocity implies that each country exchanges its commitment to reduce emissions against similar commitments by other countries. The international climate change regime described above is quite typical in this regard. It offers an arena for step-by-step cooperation and exchanges of information (monitoring). As is the case with most global governance systems, the climate regime has no centralized enforcement mechanisms but relies on monitoring instruments inside and outside the regime to identify non-complying countries, and on decentralized enforcement in the form of political and economic pressure imposed by governments and other actors on noncomplying countries.

Several cases of successful international cooperation for the provision of global public goods, such as cooperation to protect the stratospheric ozone layer, demonstrate that problems of this type can be solved. Hence the public 
goods character of climate change mitigation alone cannot explain why climate policy is progressing much slower than say cooperation in the ozone case (Barrett 2003, Oye and Maxwell 1994). The similarities and differences between the two cases, some of which are summarized in Table 1, suggest that we need to account for costs and benefits as well.

Table 1 suggests that the costs of climate change mitigation are much higher than the costs of dealing with the stratospheric ozone problem. However, as discussed in the next subsection, mitigation costs and benefits remain contested. This circumstance, together with the global public goods character of the climate change issue, makes global cooperation difficult.

Table 1: Stratospheric ozone and climate cooperation

\begin{tabular}{|c|c|c|}
\hline & $\begin{array}{l}\text { Stratospheric ozone } \\
\text { regime }\end{array}$ & $\begin{array}{l}\text { Climate change } \\
\text { regime }\end{array}$ \\
\hline $\begin{array}{l}\text { Type of } \\
\text { problem }\end{array}$ & Global public good & Global public good \\
\hline $\begin{array}{l}\text { Governance } \\
\text { structure }\end{array}$ & $\begin{array}{l}\text { Framework convention, } \\
\text { followed by protocols }\end{array}$ & $\begin{array}{l}\text { Framework conven- } \\
\text { tion, followed by } \\
\text { protocols }\end{array}$ \\
\hline $\begin{array}{l}\text { Costs (dam- } \\
\text { age) if miti- } \\
\text { gation effort } \\
\text { fails }\end{array}$ & $\begin{array}{l}\text { Short to long term, } \\
\text { clearly identifiable dam- } \\
\text { ages (e.g. higher skin } \\
\text { cancer rates, crop dam- } \\
\text { age); developing and } \\
\text { developed countries are } \\
\text { approx. equally vulner- } \\
\text { able to damages }\end{array}$ & $\begin{array}{l}\text { Medium to long } \\
\text { term damage that is } \\
\text { difficult to quantify; } \\
\text { developing coun- } \\
\text { tries are more vul- } \\
\text { nerable to damage }\end{array}$ \\
\hline $\begin{array}{l}\text { Mitigation } \\
\text { costs }\end{array}$ & $\begin{array}{l}\text { Less than \$10 billion } \\
\text { globally; substitutes for } \\
\text { ozone depleting chemi- } \\
\text { cals (ODS) are available; } \\
\text { phase-out costs are } \\
\text { spread over around 2-3 } \\
\text { decades; costs are spread } \\
\text { across a vast number of } \\
\text { consumers, but per } \\
\text { capita costs of more } \\
\text { expensive substitutes for } \\
\text { ODS are very small }\end{array}$ & $\begin{array}{l}\text { Several hundred } \\
\text { billion \$; substitutes } \\
\text { are partly available; } \\
\text { phase-out costs are } \\
\text { spread over many } \\
\text { decades; costs are } \\
\text { spread across a vast } \\
\text { number of consum- } \\
\text { ers, with rather high } \\
\text { per capita costs }\end{array}$ \\
\hline
\end{tabular}

\subsection{The contested economics of cli- mate change mitigation}

As noted above, uncertainty concerning the costs of failing to reduce GHG emissions (and, conversely, the benefits of GHG reductions) remains rather high. The same holds for the costs of reducing GHG emissions. Uncertainty with respect to benefits and costs combines to create serious difficulties in estimating the net benefits (benefits minus costs) of reducing emissions. The IPCC and the Stern Review arrive at a favorable net benefit assessment because they use rather pessimistic assumptions about climate change related damages, rather optimistic assumptions about mitigation costs, and a low discount rate. For instance, Watson (2009) argues that

- „do nothing“ would result in an average annual loss of $5-20 \%$ of global GDP now and forever due to a $50 \%$ chance of exceeding a $5^{\circ} \mathrm{C}$ temperature increase by 2100 (relative to pre-industrial levels);

- moving to a 550 ppm trajectory would result in costs of $1 \%$ of global GDP in 2050 , with a $50 \%$ change of exceeding a $3^{\circ} \mathrm{C}$ temperature rise;

- moving to a $450 \mathrm{ppm}$ trajectory would cost about $3 \%$ of GDP in 2050 and would offer a $50 \%$ change of remaining below a $2^{\circ} \mathrm{C}$ temperature increase.

In such an assessment, the ambitious 450ppm target makes sense because it offers considerable net benefits.

Net benefit estimates by other social scientists, e.g. Nordhaus (2010) and Tol (2009) are more pessimistic. The main reason is that they use higher discount rates, which leads to lower estimates of the present value of (discounted) future climate change-related damages and lower costs of mitigation the more mitigation is postponed. Based on their respective assessment, the IPCC and the Stern Review arrive at very different conclusions compared to Nordhaus, Tol, and some other economists. While the former point to large net benefits of starting early with major GHGs reductions, the latter advocate starting slowly and implementing deep cuts only in the long run. Note, however, that none of these studies denies that humaninduced climate change exists and poses very serious problems, and that major emission cuts are necessary. But they disagree on when emissions should be cut by how much in order to generate net benefits to present-day decision-makers.

It is easy to see why many policy-makers are more attracted to the Nordhaus-type estimates than the Sterntype estimates. Policies that incur rather high costs in the short-term and uncertain, even though potentially high benefits in the medium to long run are inherently less attractive than policies that generate a "return on investment" within the near future. 


\section{Measuring and Explaining Variation in National Contributions to the Global Public Good}

Most research on climate change governance concentrates on describing and explaining the climate change policies of individual countries or regions. Rather few studies focus explicitly on explaining observed variation across a large number of countries in national contributions to climate change mitigation. The following section discusses how national contributions to global climate change mitigation have been measured. The subsequent section deals with the main explanations in the existing literature.

\subsection{Measuring Variation in Contri- butions to the Public Good}

To explain differences in climate change mitigation efforts across countries, we need, first of all, indicators that provide accurate und useful information on various dimensions of national mitigation efforts. These indicators must cover two principal dimensions: policy outputs and policy outcomes. Policy outputs include laws, regulations and various other types of policy measures that can tell us how serious or ambitious a government is about climate change mitigation. Policy outcomes are phenomena located either at the interface of human behavior and the environment, such as emissions, or environmental conditions mitigation policies are aiming at, such as GHG concentrations in the atmosphere.

Existing research focuses mainly either on policy output or policy outcome, though some composite indicators have recently been developed to bundle information on different facets of climate change mitigation efforts. Economists have concentrated mainly on environmental outcomes, such as emissions, and usually explain those with economic factors (e.g. Holtz-Eakin and Selden 1995). The political science and international relations literature, in contrast, pays more attention to environmental policy- making and thus also policy output, for instance international political commitments (e.g. von Stein 2008, Bernauer et al. 2010, Sprinz and Vaahtoranta 1994). Very few studies offer a direct comparison of differences in climate change policy output and outcomes (see Congleton 1992; Bättig and Bernauer 2009, Ward 2008).

Environmental performance indicators have become quite popular in research on sustainable development in recent years (e.g. Singh et al. 2009). Yet, the construction of such composite indicators is methodologically challenging and their validity is usually contested (e.g. Böhringer and Jochem 2007, Singh et al. 2009). Freudenberg (2003: 29), for instance, advises researchers to bear the conceptual limits of composite indicators they use in mind and accompany them "by an account of their methodological limits and include detailed explanations of the underlying data set, choice of standardization technique and selection of weighting method".

To draw robust inferences about the determinants of cross-national and longitudinal variation in national climate change mitigation efforts we need data on many countries over longer periods of time. Such data is readily available for GHG emissions, and existing scientific debates focus primarily on whether explanatory models should focus on emission levels or on trends, and which GHGs and sources should be included in policy outcome variables. The largest data gap exists with respect to policy outputs. Existing large- $\mathrm{N}$ data sets for climate change policy outputs are thus far rather simple in terms of the types of policy output they capture, and they are mostly cross-sectional (e.g. Bättig and Bernauer 2009, Germanwatch 2010). Finally, large- $\mathrm{N}$ data on climate adaptation efforts does, unfortunately, not yet exist. 


\subsection{Explaining Variation in Mitiga- tion Efforts}

The most prominent explanations of variation in mitigation efforts focus on economic factors, political factors, and risk-related factors.

\section{The Environmental Kuznets Curve and related determinants}

Among economists the most popular explanation for differences in environmental behavior across countries and over time is the Environmental Kuznets Curve (EKC). ${ }^{5}$ The latter holds that an inverted $\mathrm{u}$-shaped relationship exists between income and pollution. Grossman and Krueger (1993) are usually credited for the first empirical test of the EKC (c.f. Dasgupta et al. 2002, Dinda 2004) in their study of the relationship between pollutants $\left(\mathrm{SO}_{2}\right.$ and smoke) and income per capita, where they identify such a relationship.

Recent research argues, however, that economic growth has somewhat more complex effects on pollution, including GHG emissions. Three types of effects are usually considered: a scale effect, a composition effect, and a technological effect. Since more economic output due to economic growth tends to increase pollution and waste, economic growth is assumed to have a negative scale effect on the environment. The composition effect is argued to have a positive impact on environmental performance because economies usually develop from (dirtier) manufacturing towards (cleaner) services industries. As long as the composition effect does not simply lead to a relocation of dirty production to poorer and less regulated countries, the composition effect can also reduce global (rather than only local) pollution levels. Economic growth is usually associated with technological innovations that help replace old technologies with newer and cleaner ones (technology effect). In addition, growing income is presumably associated with increasing public demand for environmental protection once a country's population has satisfied its basic needs and becomes willing to invest in "postmaterial" goods.
While the basic tenets of the EKC may well be plausible, critics argue that it conveys the message to developing countries that they should "grow first, then clean up" (Dasgupta et al. 2002: 147; Hill and Magnani 2002; and Huang et al. 2008). This has obvious implications for the discount rate (see section 2). There is a lively academic (and also policy) debate on the empirical relevance of the EKC in general and $\mathrm{CO}_{2}$ and other $\mathrm{GHG}$ emissions in partiuclar (e.g. Millimet et al. 2003; Galeotti et al. 2006). While many studies identify a statistically significant relationship between income and different local pollutants (notably, $\mathrm{SO}_{2}, \mathrm{NO}_{x}, \mathrm{CO}$; e.g. Lempert et al. 2009), global pollutants such as $\mathrm{CO}_{2}$ tend to either increase monotonically with income or have high turning points (e.g. Holtz-Eakin and Selden 1994, Dinda 2004, Neumayer 2002a). Some studies also point to a less favourable $\mathrm{N}$-shaped curve to describe the relationship between income and $\mathrm{CO}_{2}$ (e.g. Galeotti et al. 2006; Dinda 2004). Moreover, Galeotti et al. (2006) find that the inverted $u$-shaped relation for some pollutants exists for OECD countries, but not for other countries $s^{6}$. One conclusion from this research (c.f. Holtz-Eakin and Selden 1994, Huang et al. 2008) is that gambling on an automatic reduction of $\mathrm{GHG}$ emissions as income grows would be risky and probably be a mistake. ${ }^{7}$

Yet a nother problem with empirical results for the EKC is that they do not take into account regulatory policies. This implies that it remains hard to tell whether observed decreases in GHG emissions are due to income, technology, or composition effects, or whether they are caused also by effects of regulatory policies or other factors (Hill and Magnani 2002, see below). Moreover, it remains contested to what extent GHG reductions observed in some country are due to "bad" composition effects, meaning relocation of GHG-intensive production to pollution havens. The main long-term problem with "bad" composition effects is that they may allow richer countries to reap the "low-hanging" fruits and could eventually leave poor countries at the bottom of the risk-shifting cascade where beneficial composition effects must be achieved within the respective country.

${ }^{6}$ One explanation is that poorer countries are still on the upward slope of the EKC (Lempert et al. 2009)

7 Huang et al. (2008: 246) argue that an expansion of the Annex I group under the KP is necessary. 


\section{Effects of the political system}

The political system of a country is likely to have implications for climate change mitigation policy (Fredriksson and Millimet 2004a). Many studies show that democracies tend to be better providers of environmental quality (e.g. Bernauer and Koubi 2009). Even though democracy offers greater political access also for non-green interests and the median voter may not always prefer more environmental protection, existing theories expect, on balance, a positive net effect of democracy on environmental protection. The gist of the argument is that, in democracies, freedom of information and political rights enable citizens to acquire more information on environmental risks and express their demands more easily vis-a-vis policy-makers. The latter, in turn, have greater incentives than autocrats to meet citizen demands because they are more dependent on broad public support, for instance in elections (Baettig and Bernauer 2009, Gleditsch and Sverdrup 2002, Li and Reuveny 2006). Note that this argument is relative, not absolute. While the environmental performance of democracies may well be bad, the performance of nondemocracies is likely to be even worse.

Whether democracies outperform non-democracies with respect to climate change policies is largely an empirical question. Existing studies on policy outcomes (usually defined as GHG emissions) arrive at mixed results. For instance, Gleditsch and Sverdrup (2002) find that democracy is associated with lower $\mathrm{CO}_{2}$ emissions. Congleton (1992) finds that democracies emit less methane. Midlarsky (1998) observes that democarcies emit more $\mathrm{CO}_{2}$. Li \& Reuveny (2006) find that democracy is associated with less per capita $\mathrm{CO}_{2}$ emissions.

The relationship between democracy and climate policy output appears to be more robust than the relationship between democracy and climate policy outcomes (e.g. Neumayer 2002b). Von Stein (2008) observes a positive effect of democracy on climate change treaty participation. Bättig and Bernauer (2009) compare climate policy output and outcomes side-by-side. They find that democracies contribute more to the global public good in terms of policy output, i.e. political commitments, but that the effect on policy outcomes is ambiguous. They describe this result in terms of a "word-deeds" gap, which appears to be larger in democracies than in autocracies. Reasons include the fact that mitigation efforts have started only a few years ago, and that, relative to local public goods, such as air pollution, there is a stronger free-rider problem. One major research gap in this research area is whether the positive democracy effect is driven more by the demand or the supply side (e.g. Ward 2008, Baettig and Bernauer 2009).

Researchers have recently started to disaggregate democracy and examine the implications of different types of democracy, such as presidential vs. parliamentary systems, consensus democracies vs. other types, etc. Ward (2008), for instance, finds that presidential democracies perform worse than parliamentary democracies in environmental terms. Fredriksson and Millimet (2004b) observe that governments set stricter environmental policies under proportional than under majorita rian systems.

\section{Effects of the natural system}

The natural (i.e. geophysical climate) system may, on the one hand, influence the emissions behavior of countries. On the other hand, it may also affect their vulnerability to climatic changes and thus their willingness to contribute to the global public good.

Neumayer (2002a), for instance, examines natural factors such as climatic conditions, the availability of renewable and fossil fuel resources, and transportation requirements. $\mathrm{He}$ finds that these factors have significant effects on cross-country differences in $\mathrm{CO}_{2}$ emissions, though the income level remains the most important determinant. Aldy (2005) examines U.S. states and observes that climatic conditions and coal endowments are positively related to per capita $\mathrm{CO}_{2}$ emissions.

Natural system characteristics may also contribute to variation in climate risk exposure, which in turn could affect countries' willingness to commit to climate change mitigation. Sprinz and Vaahtoranta (1994), for example, argue that countries facing greater vulnerability and lower costs of cooperation are more likely to commit to stronger international environmental policies. However, empirical research on climate policy has thus far not been able to identify such a vulnerability effect. For instance, Bättig and Bernauer (2009) do not find any evidence that climate risk exposure has a positive effect on policy output or policy outcomes. Their analysis uses a climate change risk expo- 
sure index (Bättig et al. 2007) and several other indicators for risk exposure. One potential explanation for the $a b$ sence of a positive vulnerability-cooperation effect is that the available scientific information has not yet spurred sufficient public demand for risk mitigation. Another explanation is that the most vulnerable countries may have greater incentives to invest in climate adaptation, which is a national, "private" good, rather than mitigation, which is a global public good associated with positive externalities; or, they may be poor countries that are unable to invest in either adaptation or mitigation. 


\section{Alternative Forms of Climate Change Governance: Local Dynamics in Federal Systems}

\begin{abstract}
Mitigation of climate change through effective global treaties to which all countries adhere has proven very difficult. In this section we look at other forms of governance that have emerged out of this conundrum. The focus is on sub-national climate change governance. ${ }^{8}$

Local climate policy-making is particularly interesting in the case of federal political systems. One noteworthy example is the United States, a typical federal state that is also important because it accounts for around $25 \%$ of global GHG emissions, but has thus far refused to ratify the Kyoto Protocol. The absence of federal laws and regulations on GHG emissions has led to a plethora of state- and city-level initiatives over the past few years.
\end{abstract}

As of June 2010, 32 U.S. states have adopted a climate action plan, 21 states have adopted GHG emission targets, and 12 states have adaptation plans (Pew Center 2010). Furthermore, the first mandatory cap-and-trade program for $\mathrm{CO}_{2}$ in the U.S. started in 2009 for the ten member states of the Regional Greenhouse Gas Initiative (RGGI). Similar regional initiatives have been initiated in the Western U.S. states as well as in the Midwest (Pew Center 2010). At the level of cities, the U.S. Conference of Mayors Climate Protection Agreement (MCPA) is the largest agreement. It involves more than one thousand U.S. cities. It was initiated in February 2005 by the then Seattle mayor Greg Nickels. Yet another local initiative is the International Council for Local Environmental Initiatives (ICLEI)'s Cities for Climate Protection (CCP) program. The ICLEI is an international initiative that involves around 600 cities worldwide. It started in 1991 and has also helped generate political

\footnotetext{
${ }^{8}$ For reasons of space, we cannot discuss yet other forms of governance in climate policy, such as public-private partnerships and civil society involvement.
}

support for reducing local GHG emission in U.S. cities (Betsill 2001).

Such local and regional activities are interesting from an academic viewpoint. But they also beg the question of whether bottom-up activity can substitute for absent national level climate policy. Lutsey and Sperling (2007) examine the effects of decentralized climate change policies in U.S. states and cities on GHG emissions, exploring the development of emissions based on current inventories and chosen sub-national policies. They argue that "efforts of states and cities are so pervasive at this point that future federal policy will benefit by adopting the most popular and best functioning GHG mitigation programs [...]" (Lutsey and Sperling 2007: 683). Selin and VanDeever (2007) are less optimistic about the emission-reducing effects of local climate initiatives. But they also stress the importance of such programs because they allow policymakers to "[...] see which of the many available policy options are gaining support in the public and private spheres" (2007: 22) and thereby are most likely to influence future federal policy development. Tang et al. (2010) study 40 local climate change action plans in U.S. cities. They find that, although these plans reflect a high level of environmental awareness, they have only limited effects on emissions.

While existing research has not yet been able to demonstrate the effectiveness of local and regional initiatives in terms of reducing GHG emissions, recent research offers interesting insights into the factors that affect the dynamics of such initiatives. Employing event history analysis, Vasi (2006) finds that adoption of the Cities for Climate Protection (CCP) program is driven by spatial or cultural proximity to earlier adopters, and that organizational embeddedness in transnational frameworks also fosters participation. With respect to CCP county-level participation pat- 
terns, Brody et al. (2008) observe that counties with landscape characteristics of high risk, low stress, and high opportunity are more likely to join the CCP campaign. Schaffer (2010) examines county-level participation patterns for the Mayor's Climate Protection Agreement. She highlights the importance of natural system characteristics, such as whether the county is a coastal county, as well as political preferences of the inhabitants to determine where participation rates in this initiative are highest. Lee (2009) uses a multilevel setting to analyze what cities participate internationally in the CCP and other networks, such as C4O. Controlling for city and country-level variables, he finds that cities' position in the global economy and transportation hub characteristics significantly influence participation in these networks.
By and large, existing studies suggest that local and regional climate policy initiatives have gained ground in recent years, particularly in federal political systems. There is little evidence that such initiatives can substitute for slow progress in adopting and implementing ambitious mitigation policy at national and international levels. Nonetheless, evidence from the U.S. and other countries indicates that such activities can serve as policy-experiments in trying to find efficient mitigation options and changing the "mind-set" of business actors and citizens in a climatefriendly direction. 


\section{Normative Issues}

We end this chapter with a discussion of two normative issues that have received particular attention in research on climate change governance (e.g. Paterson 2001, Allen 2003, Klinsky and Dowlatabadi 2009, Vanderheiden 2008 , Posner and Sunstein 2008, Johnson 2009). One concerns intergenerational fairness, the other concerns the fair division of responsibilities for mitigation and adaptation.

As discussed above, there is strong disagreement in the scientific literature on whether and by how much future costs and benefits of climate change and its mitigation should be discounted when deciding today how much to invest in solving the problem.

Some scientists (e.g. Nordhaus 2010, Lempert et al. 2009) view the climate problem as one of many problems policymakers need to deal with in parallel; so they need to weigh the costs and benefits and decide in which policy to invest more when and where. In their view, there is, from an economic perspective, nothing that makes e.g. investment in combating infectious diseases or maintaining law and order inherently different from investment in solving an environmental problem like climate change. They also assume that future generations will be wealthier and have more technological means to mitigate climatic changes at lower cost. Hence they apply a higher discount rate to mitigation costs and also assume that damage from unmitigated climate change is less costly as it occurs in the future.

Other scientists regard this position as unethical because it burdens future generations with an environmental problem. Many of them consider that only a small or even no discount rate is the appropriate choice, and the issue should be viewed from a "rights" perspective (e.g. Collier 2010).

The policy implications of these two contrasting views are quite obvious: the former position is associated with pro- posals to start mitigation very slowly and invest more over the medium- to long-term; the latter position generates proposals to "front-load" mitigation efforts, i.e., start early and invest a lot in the short- to medium-term. However, most a nalysts agree that there is no scientific solution that could identify the "correct" discount rate.

Yet another issue that has attracted considerable attention in social sciences research is the question of fair burden sharing in mitigation and adaptation. Since past and current emissions have a greenhouse effect over many years to come and predictions of future emissions vary greatly, researchers have used complex models to calculate how much particular countries and regions contribute to global warming. A paper by Elzen et al. (2005), for instance, shows that responsibilities of specific regions can be calculated, though these responsibilities differ somewhat depending on the time period of emissions, the mix of GHG, climate impact indicators, and climate models. Such calculations indicate what share in temperature increases can be attributed to specific countries or regions. Elzen et al. find that the average contributions to the global mean surface temperature increase in the year 2000 amount to around 40\% for OECD countries, $14 \%$ for Eastern Europe and the Former Soviet Union, 24\% for Asia, and $22 \%$ for Africa and Latin America. The OECD share decreases when later attribution periods are selected and increases for industrial latecomers, such as Asia. Including land-use related GHG emissions tends to reduce the OECD share at the expense of other regions. Other authors, e.g. Böhringer and Helm (2008) have sought to come up with specific modes of fair division based on compensation schemes. Again, such calculations show that normative assumptions (e.g. how industrial latecomers should be treated, which GHG should be considered) play an important role in establishing responsibilities for and, consequently, also burden-sharing formulas for climate change mitigation. 
Finally, another line of research assumes that climaterelated damage is unavoidable even with the most ambitious mitigation efforts. Accordingly, it asks who should pay for adaptation measures. Dellink et al. (2009) use two principles, historical responsibility for radiative forcing and capacity to pay, to estimate the shares of individual countries in the financial burden. The results turn out to be more sensitive with respect to variation in capacity to pay assumptions than model input concerning historical responsibility. The authors assume adaptation costs of USD 100 billion per year and conclude that Annex I countries should contribute around USD 65-70 billion, which amounts to around USD 43-82 per capita and year in Annex I countries and USD 1-21 in non-Annex I countries. 


\section{References}

Adger, W. N. 2010. "Climate Change, Human Well-Being and Insecurity." New Political Economy 15 (2): 2-16.

Aldy, Joseph. 2005. "An Environmental Kuznets Curve Analysis of U.S. State-Level Carbon Dioxide Emissions." The Journal of Environment \& Development 14 (1): 4872.

Allen, M. 2003. "Lia bility for climate change." Nature 421 (6926):891-2.

Allen, M., D. Frame, K. Frieler, W. Hare, C. Huntingford, C. Jones, R. Knutti, J. Lowe, M. Meinshausen, and N. Meinshausen. 2009. "The exit strategy." Nature Reports Climate Change: 56-8.

Baettig, M. B., and T. Bernauer. 2009. "National Institutions and Global Public Goods: Are Democracies More Cooperative in Climate Change Policy?" International Organization 63(02): 281-308.

Baettig, M. B., M. Wild, and D. Imboden. 2007. "A climate change index: Where climate change may be most prominent in the 21st century." Geophysical Research Letters 34:1-6.

Barrett, S. 2003. Environment and statecraft: the strategy of environmental treaty-making. Oxford: Oxford University Press.

Bernauer, T., and V. Koubi. 2009. "Effects of political institutions on air quality." Ecological Economics 68 (5):135565.

Bernauer,T., V. Koubi, A. Kalbhenn, and G. Ruoff. 2010. Climate Change, Economic Growth, and Conflict. Paper read at Climate Change and Security, 21-24 June 2010, at Trondheim, Norway.

Bernauer,T., V. Koubi, A. Kalbhenn, and G. Ruoff. 2010 (forthcoming). A Comparison of International and Domestic Sources of Global Governance Dynamics: Explaining Global Environmental Treaty Ratifications, 1950-2000. British Journal of Political Science.
Betsill, Michele. 2001. "Mitigating Climate Change in US Cities: opportunities and obstacles." Local Environment $6(4): 393-406$

Betsill, Michele, and Harriet Bulkeley. 2006. "Cities and the Multilevel Governance of Global Climate Change." Global Governance 12 (2):141-59.

Böhringer, C., and C. Helm. 2008. "On the fair division of greenhouse gas abatement cost." Resource and energy economics 30 (2):260-76.

Böhringer, C, and P Jochem. 2007. "Measuring the immeasurable - A survey of susta inability indices." Ecological Economics.

Buhaug, H., N. P. Gleditsch, and O. M. The isen. 2008. Implications of climate change for armed conflict. Paper read at Social Dimensions of Climate Change, at Washington, D.C.

Burke, M. B., E. Miguel, S. Satyanath, J. A. Dykema, and D. B. Lobell. 2009. "Warming increases the risk of civil war in Africa." Proceedings of the National Academy of Sciences 106 (49):20670-74.

Collier, P. 2010. The Plundered Planet: Why We Must - and How We Can - Manage Nature for Global Prosperity. Oxford: Oxford University Press.

Congleton, R. D. 1992. "Political institutions and pollution control." The review of economics and statistics 74 (3):412-21.

Cline, W. R. 1999. "Discounting for the very long term." In Discounting and intergenerational equity, ed. P. R. Portney and J. P. Weyant. Washington: Resources for the Future.

Dasgupta, Susmita, Benoit Laplante, Hua Wang, and David Wheeler. 2002. "Confronting the Environmental Kuznets Curve." Journal of Economic Perspectives 16 (1):147-68. 
de Bruyn, S. M., and R. J. Heintz. 1998. "The Environmental Kuznets Curve hypothesis". In Handbook of environmental economics. Oxford: Blackwell Publishing

Dell, M., B. F. Jones, and B. A. Olken. 2008. "Climate shocks and economic growth: Evidence from the last half century." NBER Working Paper 14132.

Dellink, R., M. Elzen, H. Aiking, E. Bergsma, F. Berkhout, T. Dekker, and J. Gupta. 2009. "Sharing the burden of financing adaptation to climate change." Global Environmental Change 19 (2009):411-21.

Den Elzen, M. G. J., M. Schaeffer, and P. L. Lucas. 2005. "Differentiating future commitments on the basis of countries relative historical responsibility for climate change: uncertainties in the Brazilian Proposal in the context of a policy implementation." Climatic Change 71 (3):277-301.

Dinda, S. 2004. "Environmental Kuznets curve hypothesis: a survey." Ecological Economics 49 (4):431-55.

Fredriksson, P. G., and D. L. Millimet. 2004a. "Comparative politics and

environmental taxation." Journal of Environmental Economics and Management 48(1):705-22.

Fredriksson, P. G., and D. L. Millimet. 2004b. "Electoral rules and environmental policy." Economics Letters 84

(2):237-44

Freudenberg, M. (2003), "Composite Indicators of Country Performance: A Critical Assessment", OECD Science, Technology and Industry Working Papers, 2003/16, OECD Publishing.

Füssel, H. M. 2010. "Modeling impacts and adaptation in global IAMs." Wiley Interdisciplinary Reviews: Climate Change 1 (March/April):288-303.

Galeotti, M, A Lanza, and F Pauli. 2006. "Reassessing the environmental Kuznets curve for $\mathrm{CO}_{2}$ emissions: A robustness exercise." Ecological Economics 57 (1):152-63.

Gemmill, B., and A. Bamidele-Izu. 2002. "The role of NGOs and civil society in global environmental governance." In Global Environmental Governance: Options \& Opportunities, ed. D. C. Esty and M. H. Ivanova. New Haven: Yale School of Forestry and Environmental Studies.
Germanwatch 2010 "Klimaschutzindex 2010" accessed at www.germanwatch.org/ksi

Gleditsch, N. P., and B. O. Sverdrup. 2002. "Democracy and the environment." In Human security and the environment: international compa risons, ed. E. Page and M. R. Redclift. Cheltenham: Edward Elgar.

Grossman, G.M., A.B. Krueger. 1995. "Economic Growth and the Environment." The Quarterly Journal of Economics $110(2): 353-377$.

Hardin, G. 1968. "The tragedy of the commons." Science 162 (3859):1243-8.

Hill, R. J., and E. Magnani. 2002. "An exploration of the conceptual and empirical basis of the environmental Kuznets curve." Australian Economic Papers 41 (2):23954 .

Holtz-Eakin, D, and T Selden. 1995. "Stoking the fires? $\mathrm{CO}_{2}$ emissions and economic growth." Journal of Public Economics 57 (1):85-101.

Huang, W, G Lee, and C Wu. 2008. "GHG emissions, GDP growth and the Kyoto Protocol: A revisit of Environmental Kuznets Curve hypothesis." Energy Policy 36 (1):239-47.

IPCC. 2007. "Climate Change 2007: The Physical Science Basis; Summa ry for Policymakers." Fourth Assessment Report, Geneva: IPCC.

IPCC, 2007. "Summary for Policymakers." In: Climate Change 2007: Impacts, Adaptation and Vulnerability. Contribution of Working Group II to the Fourth Assessment Report of the Intergovernmental Panel on Climate Change, M.L. Parry, O.F. Canziani, J.P. Palutikof, P.J. van der Linden and C.E. Hanson, Eds., Cambridge University Press, Cambridge, UK: 7-22.

Johnson, S. 2009. "Climate Change and Global Justice: Crafting Fair Solutions for Nations and Peoples." Harvard Environmental Law Review 33:297-301.

Klinsky, S., and H. Dowlatabadi. 2009. "Conceptualizations of justice in climate policy." Climate Policy 9 (1):88-108.

Lee, T. 2009 "Why do Cities Participate (or not) in the Global Climate Change Network(s)?" Paper presented at the ISA's 5oth ANNUAL CONVENTION "EXPLORING THE PAST, ANTICIPATING THE FUTURE", New York. 
Lempert, Robert, Jürgen Scheffran, and Detlef Sprinz. 2009. "Methods for Long-Term Environmental Policy Challenges" Global Environmental Politics 9 (3):106-33.

Li, Q., and R. Reuveny. 2006. "Democracy and environmental degradation."

International Studies Quarterly 50:935-56.

Lutsey, N., and D. Sperling. 2007. "Ame rica's bottom-up climate change mitigation policy." Energy Policy 36:67385 .

Midlarsky, M. I. 1998. "Democracy and the environment: An empirical assessment." Journal of Peace Research 35 (3):341-61.

Miguel, E., S. Satyanath, and E. Sergenti. 2004. "Economic shocks and civil conflict: An instrumental variables approach." Journal of Political Economy 112 (4):725-53.

Millimet, Daniel L, John A List, and Thanasis Stengos. 2003. "The Environmental Kuznets Curve: Real Progress or Misspecified Models?" The review of economics and statistics $85(4): 1038-47$.

Mitchell, R. B. 2006. "Problem structure, institutional design, and the relative effectiveness of international environmental agreements." Global Environmental Politics $6(3): 72-89$.

Neumayer, E. 2002a. "Can natural factors explain any cross-country differences in carbon dioxide emissions?" Energy Policy 30 (1):7-12.

Neumayer, Eric. 2002b. "Do Democracies Exhibit Stronger International Environmental Commitment? A Crosscountry Analysis." Journal of Peace Research 39 (2):13964.

Nordhaus, W. 2010. "Economic Aspects of Global Warming in a Post-Copenhagen Environment." New Haven: Yale University, February 3, 2010.

Ostrom, E., R. Gardner, and J. Walker. 1994. Rules, games, and common-pool resources. Ann Arbor: University of Michigan Press.

Oye, K.A. and J.H. Maxwell. 1994 "Self-Interest and Environmental Management," Journal of Theoretical Politics, 6 (4): 593-624.
Paterson, M. 2001. "Principles of justice in the context of global climate change." In International Relations and Global Climate Change, ed. U. Luterbacher and D. F. Sprinz. Cambridge, MA: MIT Press.

Pew Center 2010at www.pewclimate.org/what_s_being done/in_the_states/state_action_maps.cfm

Posner, E. A., and C. R. Sunstein. 2007. "Climate Change Justice." Georgetown Law Journal 96:1565-612.

Rogelj, J., J. Nabel, C. Chen, W. Hare, K. Markmann, M. Meinshausen, M. Schaeffer, K. Macey, and N. Höhne. 2010. "Copenhagen Accord pledges a re paltry." Nature 464 (7292):1126-8.

Sandler, T. 1997. Global challenges: a n approach to environmental, political, and economic problems. Cambridge: Cambridge University Press.

Schaffer, L.M. 2009 "Is Space more than Geography? Testing Spatial Dependence of Participation in Voluntary Climate Change Initiatives" Paper presented at the Midwest Political Science Association 67th Annual National Conference in Chicago

Schaffer, L.M. 2010 "Nature, Nurture or Neighbors? Testing Participation Patterns in Voluntary Initiatives in U.S. Counties" paper presented at the Annual Meeting of the Swiss Political Science Association in Geneva.

Schwartz, P., and D. Randall. 2003. "An abrupt climate change scenario and its implications for United States national security." Prepared for the Department of Defense by the Global Business Network.

Selin, Henrik, and Stacy VanDeveer. 2007. "Political Science and Prediction: What's Next for U.S. Climate Change Policy?" Review of Policy Research 24 (1):1-27.

Singh, R, H Murty, S Gupta, and A Dikshit. 2009. "An overview of sustainability assessment methodologies." Ecological indicators 9: 189-212.

Sprinz, D., and T. Vaahtoranta. 2009. "The interest-based explanation of international environmental policy." International Organization 48 (01):77-105.

Stavins, R. N. 2003. "Experience with market-based environmental policy instruments." In Handbook of environmental economics, ed. K.-G. Mäler and J. R. Vincent. Amsterdam: Elsevier. 
Stern, N., S. Peters, V. Bakhshi, A. Bowen, C. Cameron, S. Catovsky, D. Crane, S. Cruickshank, and S. Dietz. 2006. Stern Review on the Economics of Climate Change. London: HM Treasury.

Stern, N. 2008. "The economics of climate change." American Economic Review 98 (2):1-37.

Tang, Z., S. Brody, C. Quinn, L. Chang, and T. Wei. 2010. "Moving from agenda to action: evaluating local climate change action plans." Journal of Environmental Planning and Management 53 (1): 41-62

Theisen, O.M.; H. Holtermann and H. Buhaug, 2010. "Drought, Political Exclusion, and Civil War", presented at International Studies Association Annual Convention, New Orleans, LA, 17-20 February.

Tol, R. S. J., and G. W. Yohe. 2006. "A review of the Stern Review." World Economics 7 (4):233-50.
Vanderheiden, S. 2008. Atmospheric justice: A political theory of climate change. Oxford: Oxford University press.

Vasi, Ion. 2006. "Organizational Environments, Framing Processes, and the Diffusion of the

Program to Address Global Climate Change Among Local Governments in the United

States." Sociological Forum 21:439-66.

Von Stein, J. 2008. "The international law and politics of climate change: Ratification of the United Nations Framework Convention and the Kyoto Protocol." Journal of Conflict Resolution 52 (2): 243.

Ward, H. 2008. "Liberal democracy and susta inability." Environmental Politics 17 (3):386-409. 


\section{List of IED working papers}

- Renate Schubert, Julia Blasch, and Kristin Hoffmann (2007). Environmental Protection, Energy Policy and Poverty Reduction - Synergies of an Integrated Approach. IED Working Paper 1, ETH Zurich, Institute for Environmental Decisions, Chair of Economics.

- Robert Finger and Werner Hediger (2007). The application of robust regression to a production function comparison - the example of Swiss corn. IED Working Paper 2, ETH Zurich, Institute for Environmental Decisions, Agri-Food and Agri-Environmental Economics Group.

- Stefanie Engel and Charles Palmer (2008). "Painting the forest REDD?" Prospects for mitigating climate change through reducing emissions from deforestation and degradation. IED Working Paper 3, ETH Zurich, Institute for Environmental Decisions, Chair of Environmental Policy and Economics.

- Lasse Wallquist and Mischa Werner (2008). Carbon dioxide Capture and Storage - CCSStudie zum Entwicklungsstand von CCS in der Schweiz. IED Working Paper 4, ETH Zurich, Institute for Environmental Decisions, Chair of Consumer Behavior.

- Roland W. Scholz and Michael Siegrist (2008). Low Risks, High Public Concern? The Cases of Persistent Organic Pollutants (POPs), Heavy Metals, and Nanotech Particles. IED Working Paper 5. ETH Zurich, Institute for Envi- ronmental Decisions, Chair of Natural and Social Science Interface, Chair of Consumer Behavior.

- Astrid Zabel, Karen Pittel, Göran Bostedt, and Stefanie Engel (2009). Comparing Conventional and New Policy Approaches for Carnivore Conservation - Theoretical Results and Application to Tiger Conservation. IED Working Paper 6, ETH Zurich, Institute for Environmental Decisions, Chair of Environmental Policy and Economics.

- Astrid Zabel and Brian Roe (2009) Performance payments for environmental services: Lessons from economic theory on the strength of in centives in the presence of performance risk and performance measurement distortion. IED Working Paper 7, ETH Zurich, Institute for Environmental Decisions, Chair of Environmental Policy and Economics.

- Stefanie Engel and Charles Palmer (2009). The Complexities of Decentralization in a Globalizing World. IED Working Paper 8, ETH Zurich, Institute for Environmental Decisions, Chair of Environmental Policy and Economics.

- Michael Hartmann, Robert Huber, Simon Peter, and Bernard Lehmann (2009). Strategies to mitigate greenhouse gas and nitrogen emissions in Swiss agriculture: the application of an integrated sector model. IED Working Paper 9, ETH Zurich, Institute for Environmental Decisions, Agri-Food and Agri-Environmental Economics Group.
- Julia Blasch, Renate Schubert, Birgit Soete (2010). Grün aus der Krise Was können "grüne» Konjunkturpakete leisten? IED Working Paper 10, ETH Zurich, Institute for Environmental Decisions, Chair of Economics.

Moritz Rohling und Markus Ohndorf (2010). Prices vs. Quantities with Fiscal Cushioning. IED Working Paper 11, ETH Zurich, Institute for Environmental Decisions, Chair of Economics.

- Thomas Bernauer and Lena Maria Schaffer (2010). Climate Change Governance. IED Working Paper 12, ETH Zurich, Institute for Environmental Decisions, Chair of International Relations.

- Markus Ohndorf (2010). Optimal Monitoring for project-based Emissions Trading Systems under incomplete Enforcement. IED Working Paper 13, ETH Zurich, Institute for Environmental Decisions, Chair of Economics.

- Justin Caron and Markus Ohndorf (2010). Irreversibility and Optimal Timing of Climate Policy. IED Working Paper 14, ETH Zurich, Institute for Environmental Decisions, Chair of Economics. 
TH Zurich

Institute for Environmental Decisions IED

WEHG

CH-8092 Zurich

SWITZERLAND

Phone +41446324718

Fax +41446321042

URL http://www.ied.ethz.ch 